\title{
O setor agroexportador brasileiro no contexto da integração Mercosul/UE 1
}

\author{
Norberto Martins Vieira ${ }^{2}$ \\ Fátima Marília Andrade de Carvalho ${ }^{3}$
}

Resumo: A partir da perspectiva de constituição do acordo Mercosul/UE, com possibilidade de fortalecimento do comércio entre os blocos, foram analisados, por meio da estimação da criação e do desvio de comércio para o setor agroexportador brasileiro, os possíveis ganhos em dois cenários alternativos de integração. Foi utilizado um modelo de equilíbrio parcial, cujos resultados para os dois níveis de redução tarifária confirmaram as expectativas de que a integração Mercosul/UE proporcionaria significativos ganhos comerciais para o agronegócio brasileiro. Além disso, as estimativas de criação de comércio foram, na maior parte das simulações, superiores às de desvio de comércio, evidenciando a eficiência produtiva e competitividade do setor agroexportador brasileiro na economia mundial.

Palavras-chaves: integração Mercosul/UE; equilíbrio parcial e criação e desvio de comércio.

Abstract: From the prospect of implementation of the Mercosul/UE agreement, which should allow the strengthening of the trade between the two blocks, we analyzed the possible gains in two alternative scenarios of integration using a Partial Equilibrium Model for the

\footnotetext{
${ }^{1}$ Os autores agradecem a Capes e Fapemig pelo apoio financeiro e também aos pareceristas anônimos pelos comentários, pelas críticas e sugestões.

${ }^{2}$ Doutorando em Economia Aplicada na Universidade Federal de Viçosa (UFV), Departamento de Economia Rural. E-mail: norbertoufv@yahoo.com.br

${ }^{3}$ Doutora em Economia Agrária pela Escola Superior de Agricultura Luiz de Queiroz (Esalq), USP, e Professora Associada do Departamento de Economia Rural, da Universidade Federal de Viçosa (UFV).E-mail: fmac@ufv.br
} 
estimation of trade creation and trade deviation in the Brazilian Agricultural Export Sector. The results for the two levels of tariff reduction confirmed the expectations that the integration Mercosul/UE would provide significant commercial gains for the Brazilian agribusiness. In addition, the estimates of trade creation were for most of the simulations superior to those of trade deviation, confirming the productive efficiency and competitiveness of the Brazilian Agricultural Export Sector in the world economy.

Key-words: Mercosul/UE integration, partial equilibrium, tradecreation and trade deviation.

Classificação JEL: Q17.

\section{Introdução}

A maior participação do Brasil no mercado exportador agrícola mundial ainda está em construção. O País desenvolve esforços de integração comercial internacional cujos resultados podem ser significativos para os seus diferentes setores produtivos. Uma das prioridades da política externa brasileira - o relacionamento com a Europa Ocidental - caracteriza-se tanto pela intensidade do diálogo político como pelo dinamismo do intercâmbio econômico.

O Brasil tornou-se uma importante fonte de importações da UE, bem como a espinha dorsal das futuras relações comerciais entre Mercosul e UE. A evolução desse comércio bilateral tem mostrado uma tendência de crescimento. De acordo com os dados do Ministério do Desenvolvimento, Indústria e Comércio Exterior (MDIC), a partir do início dos anos 90, as importações brasileiras provenientes da UE, até então sistematicamente inferiores às suas exportações, apresentaram aumento vigoroso, passando de US\$ 5 bilhões em 1991 para valor próximo a US\$ 17 bilhões no ano de 1998, chegando a atingir cerca de US\$ 18 bilhões em 2005 . Por sua vez, as exportações brasileiras para o bloco apresentaram uma trajetória de crescimento mais uniforme no período de 1990/2003, atingindo US\$ 18,5 bilhões em 2003, com um grande impulso observado nos últimos anos, atingido US\$26,5 bilhões em 2005, sendo o saldo comercial novamente superavitário a partir de 2002.

$\mathrm{O}$ acesso restrito ao mercado comunitário, devido às altas tarifas sobre os produtos agrícolas, nos quais os países do Mercosul têm vantagem natural, aumenta significativamente os benefícios potenciais de uma área de livre comércio entre europeus e sul-americanos. As características da produção dos dois lados representam ganhos potenciais não desprezíveis no caso da concretização de um processo integrativo. As alterações tarifárias no comércio intra-regional, como conseqüência de um processo de integração, podem gerar benefícios trazidos pelo efeito de criação de comércio entre os blocos. As negociações Mercosul/UE estão centralizadas, por parte do Mercosul, na questão 
agrícola e, por parte da União Européia, no acesso a serviços, investimentos e compras governamentais, além dos produtos industriais.

A União Européia possui um modelo de integração bastante específico, que segue um padrão definido desde sua criação, em 1957, e que vem ao longo dos anos ampliando o número de estados membros, que passou de 15 para 25 , com a entrada de 10 países do Leste Europeu em 2004. Com essa ampliação, há perspectivas de maiores dificuldades ainda de acesso do Mercosul ao mercado europeu, já que a maioria dos novos membros tem a agricultura como força exportadora. A questão do protecionismo se situa na base de um acordo Mercosul/UE, em que os interesses europeus estão além da esfera comercial, estendendo-se para a área dos investimentos diretos e serviços.

Nesse cenário de impasses nas negociações, estudos que possam contribuir na verificação dos efeitos desse processo de integração comercial ganham importância. Estudos como De Negrie Arbache (2003), Cypriano e Teixeira (2003) e Kume et al. (2004) abordaram alguns aspectos dessas questões, especificamente para o Mercosul e o Brasil. O presente trabalho visou contribuir com essas pesquisas, incorporando uma estimativa diferenciada a respeito dos ganhos comerciais para o Brasil na perspectiva de um acordo comercial entre Mercosul e UE. Além de a análise concentrar-se na pauta agroexportadora brasileira para a UE, devido a sua grande importância, o trabalho se diferencia ao estimar os ganhos comerciais já admitindo a incorporação dos novos membros ao bloco europeu. Dessa forma, os resultados refletem estimativas sobre a problemática da concorrência que os produtos brasileiros enfrentarão por conta da entrada dos países do Leste Europeu, que são tradicionalmente exportadores de bens agrícolas, na UE.

Na perspectiva atual de constituição do acordo Mercosul/UE, com possibilidade de fortalecimento do comércio entre os blocos, este trabalho procurou determinar, com base no comércio Brasil/UE dos anos de 2004 e 2005, os efeitos de criação e desvio de comércio que prevaleceriam nas relações comerciais brasileiras do agronegócio - setor estratégico para o Brasil.

\section{2. $\mathrm{O}$ relacionamento Mercosul/UE}

Na esfera comercial, o relacionamento Mercosul/UE é marcado por uma grande assimetria no que se refere à importância de cada bloco para seu parceiro. Em 2005, segundo dados do Gabinete de Estatísticas da União Européia (Eurostat, 2006) a UE foi um dos principais parceiros do Mercosul, tendo participado com cerca de $21 \%$ nas exportações e $18 \%$ nas importações totais desse bloco. Por outro lado, nesse mesmo ano, o Mercosul foi responsável por apenas 1,9\% das exportações e 2,6\% das importações extrabloco da UE. 
O aumento das exportações do Mercosul para a UE ocasionou uma inversão da situação da balança comercial entre os blocos. No ano de 2000, as exportações do Mercosul pra a UE totalizaram US\$ 19.708 milhões, enquanto suas importações corresponderam a US\$ 20.254 milhões, implicando um déficit com o bloco europeu de US\$ 546,2 milhões (Figura 1).

Figura 1. Comércio total entre Mercosul e UE no período de 2000 a 2005, em 1.000 US\$.

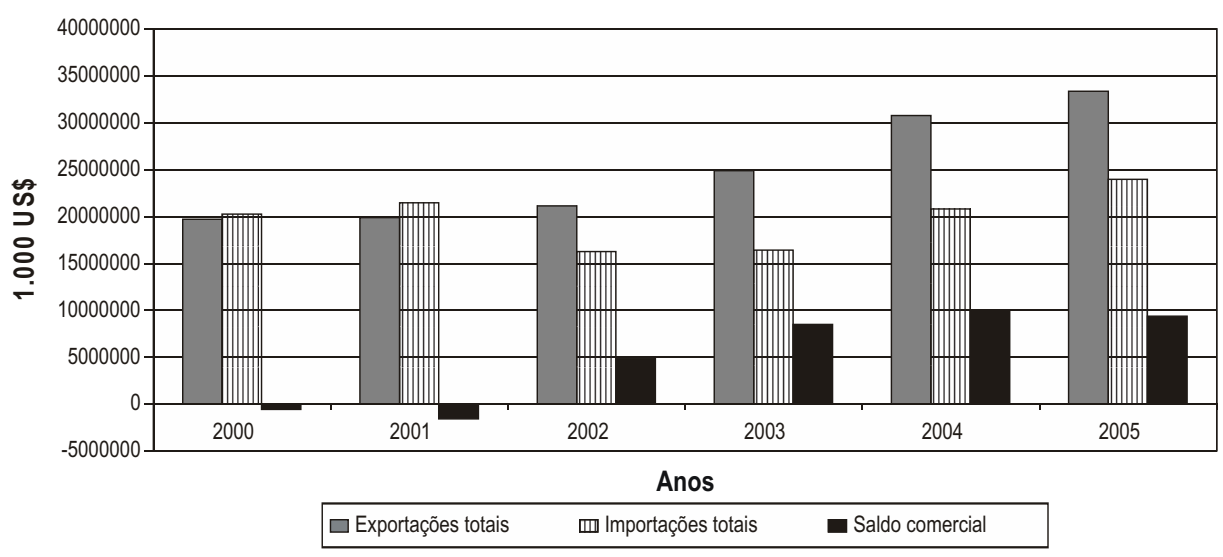

Fonte: Eurostat (2006).

A partir de 2002, o saldo comercial do Mercosul com a UE passou a ser superavitário. No ano de 2005, o bloco sul-americano obteve saldo positivo de US\$ 9.337 milhões, tendo exportado aproximadamente US\$ 33.348 milhões e importado, US\$ 23.971 milhões de seu parceiro europeu. O Brasil destacou-se como maior exportador e importador do bloco europeu. Em 2005, somente o Brasil foi responsável por $76 \%$ das exportações e por $78 \%$ das importações totais da UE (Eurostat, 2006).

Uma característica marcante no padrão de comércio Mercosul/UE é a importância dos produtos agropecuários ${ }^{4}$ na pauta de exportação dos sul-americanos. A Figura 2 destaca o predomínio desses produtos nas exportações com destino à UE.

No ano de 2000, as exportações agrícolas do Mercosul para o bloco europeu totalizaram US\$19.708 milhões -53,6\% do total exportado. Apesar do avanço nas exportações de outros produtos, ao longo do período de 2000 a 2005, a pauta exportadora para a UE foi predominantemente agrícola, atingindo, nesse último ano, 53,9\% do valor total exportado.

\footnotetext{
${ }^{4}$ Abrange os capítulos 01 a 24 do Sistema Harmonizado.
} 
Figura 2. Exportações totais e agrícolas do Mercosul para a UE no período de 2000 a 2005, em 1.000 US\$.

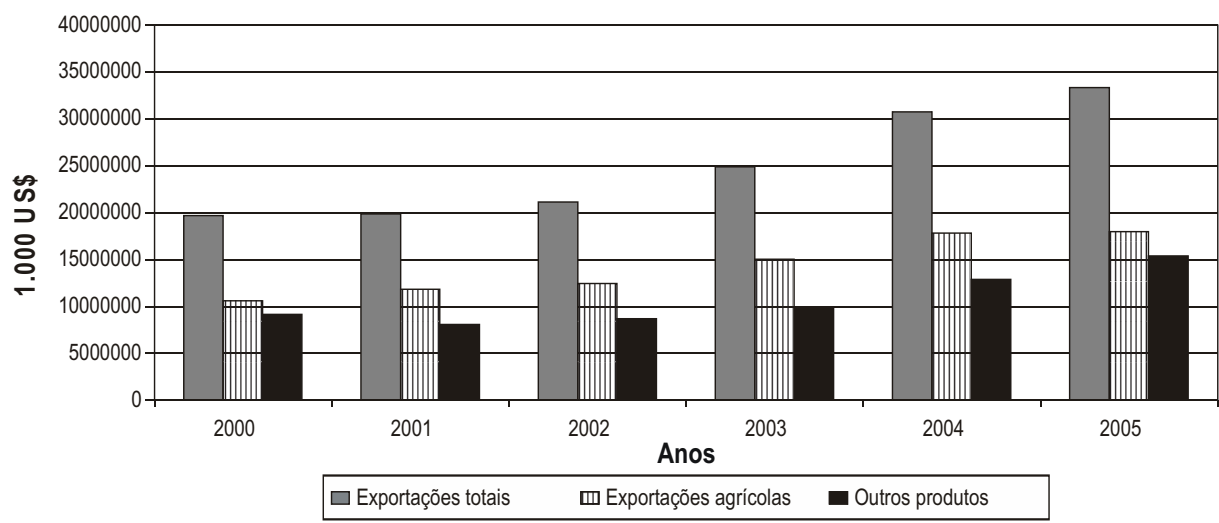

Fonte: Eurostat (2006).

Considerando-se apenas o comércio dos produtos de origem agropecuária, o Mercosul passou ser um importante parceiro da UE; destacaram-se, em 2005, as carnes, os grãos e sementes e os resíduos das indústrias alimentares (Eurostat, 2006).

Tabela 1. Exportações agrícolas do Mercosul para a UE em 2005, por capítulo do Sistema Harmonizado (SH), em 1.000 US\$, e a participação nas exportações agrícolas do Mercosul

\begin{tabular}{llrr}
\hline Capítulo & Descrição do capítulo & $\begin{array}{r}\text { Valor } \\
\text { exportado }\end{array}$ & $\begin{array}{r}\text { Participação } \\
\mathbf{( \% )}\end{array}$ \\
\hline 01 & Animais vivos. & 9.648 & 0,05 \\
02 & Carnes e miudezas, comestíveis. & 2.006 .374 & 11,17 \\
03 & Peixes e crustáceos, moluscos e outros. & 804.301 & 4,48 \\
04 & Leite e laticínios, ovos, mel natural. & 132.617 & 0,74 \\
05 & Outros produtos de origem animal. & 156.784 & 0,87 \\
06 & Plantas vivas e produtos de floricultura. & 22.871 & 0,13 \\
07 & Produtos hortícolas, plantas e raízes. & 106.657 & 0,59 \\
08 & Frutas, cascas de cítricos e de melóes. & 1.340 .230 & 7,46 \\
09 & Café, chá, mate e especiarias. & 1.568 .632 & 8,73 \\
10 & Cereais. & 245.959 & 1,37 \\
11 & Produtos da indústria de moagem. & 3.199 & 0,02 \\
12 & Sementes e frutos oleaginosos e grãos. & 3.110 .945 & 17,32 \\
13 & Gomas, resinas e outros sucos. & 13.902 & 0,08 \\
14 & Matérias para trançaria e outros. & 1.976 & 0,01 \\
15 & Gorduras, óleos e ceras animais e vegetais. & 574.803 & 3,20 \\
\hline
\end{tabular}


Tabela 1. Continuação.

\begin{tabular}{llrr}
\hline Capítulo & Descrição do capítulo & $\begin{array}{r}\text { Valor } \\
\text { exportado }\end{array}$ & $\begin{array}{r}\text { Participação } \\
\mathbf{( \% )}\end{array}$ \\
\hline 16 & Preparações de carne, de peixes e outros. & 747.179 & 4,16 \\
17 & Açúcares e produtos de confeitaria. & 79.823 & 0,44 \\
18 & Cacau e suas preparações. & 55.369 & 0,31 \\
19 & Preparações à base de cereais e farinhas. & 6.210 & 0,03 \\
20 & Preparações de produtos hortícolas e de frutas. & 801.258 & 4,46 \\
21 & Preparações alimentícias diversas. & 86.572 & 0,48 \\
22 & Bebidas, líquidos alcoólicos e vinagres. & 272.740 & 1,52 \\
23 & Resíduos das indústrias alimentares. & 5.263 .664 & 29,30 \\
24 & Fumo e seus sucedâneos. & 553.096 & 3,08 \\
\hline Total das exportações agrícolas & $\mathbf{1 7 . 9 6 4 . 8 1 8}$ & $\mathbf{1 0 0 , 0 0}$ \\
\hline Fonte: Eurostat (2006), elaboração do autor. & &
\end{tabular}

As exportações agrícolas do Mercosul para a UE totalizaram em 2005 aproximadamente US\$ 18 bilhões. Grande parcela desse total $(57,8 \%)$ refere-se aos produtos que compõem apenas três Capítulos de exportação: Capítulo 02 (Carnes e miudezas, comestíveis), responsável por 11,2\%; Capítulo 12 (Sementes e frutos oleaginosos e grãos), com 17,3\% ; e o Capítulo 23 (Resíduos das indústrias alimentares), que apresentou maior parcela nas exportações agrícolas para a UE em 2005 , cerca de $29 \%$.

\section{Metodologia}

\subsection{O modelo de equilíbrio parcial}

Modelar os impactos dos acordos de livre comércio que um país faz tem se tornado especialmente relevante por conta dos diversos acordos regionais de comércio que têm sido realizados. Existem duas formas de modelar um acordo de livre comércio: ou se usam os modelos de equilíbrio geral, ou, alternativamente, aplicam-se modelos de equilíbrio parcial. Segundo Maciente (2000) embora o modelo de equilíbrio parcial seja vulnerável a críticas por não levar em conta os efeitos de grandes mudanças na economia, ele tem a vantagem de trabalhar em um alto nível de detalhes, como considerar com precisão a identificação de produtos ou grupo de produtos (capítulos). A necessidade de se obterem estimativas desagregadas do impacto da liberalização comercial do Brasil com a União Européia levou à opção de se trabalhar com modelos de equilíbrio parcial.

As simulações realizadas neste trabalho têm como base o modelo de equilíbrio parcial apresentado em Laird e Yeats (1990). Trata-se de um modelo estático, que calcula os efeitos de primeira ordem de reduções tarifárias 
incidentes sobre as importações provenientes de um determinado país. Como mencionado, uma redução das barreiras leva a um aumento do comércio, que pode ser desmembrado em dois componentes: criação de comércio - parte do aumento das importações devido ao barateamento dos produtos resultante da redução das barreiras; e desvio de comércio - parte do aumento devido à substituição dos fornecedores. Se o parceiro que recebe tratamento preferencial for o fornecedor mais eficiente, não haverá desvio de comércio.

O cálculo da criação de comércio foi feito com base na equação 1:

$$
\mathrm{TC}_{\mathrm{ijk}}=\mathrm{M}_{\mathrm{ijk}} \cdot \mathrm{E}_{\mathrm{m}} \cdot \mathrm{dt}_{\mathrm{ijk}} /\left(1+\mathrm{t}_{\mathrm{ijk}}\right)
$$

em que: TC é a criação de comércio; i, o índice referente ao produto; j, o índice referente ao país importador; $\mathrm{k}$, o índice referente ao país exportador; $\mathrm{M}$, as importações totais; $E_{m}$, a elasticidade de demanda das importações; $d$, o prefixo que indica variação; e t, a tarifa e/ou barreiras não-tarifárias (equivalente ad valorem).

A equação (1) permite uma interpretação relativamente simples. A redução na tarifa causa uma variação no preço $\left[(\Delta \mathrm{P} / \mathrm{P})=\mathrm{dt}_{\mathrm{i}} /\left(1+\mathrm{t}_{\mathrm{ijk}}\right)\right]$, que, multiplicada pela elasticidade-preço da importação e pelo valor das importações no ano escolhido, fornece a variação nas importações.

Para modelagem de desvio de comércio, a fórmula usual é:

$$
T D_{i j k}=\frac{M_{i j k}}{\sum M_{i j k}} \cdot \frac{\sum M_{i j k} \cdot \sum M_{i j K} \cdot E_{s} \cdot \Delta\left(P_{i j k} / P_{i j K}\right) /\left(P_{i j k} / P_{i j K}\right)}{\sum M_{i j k}+\sum M_{i j K}+\sum M_{i j K} \cdot E_{s} \cdot \Delta\left(P_{i j k} / P_{i j K}\right) /\left(P_{i j k} / P_{i j K}\right)}
$$

em que: TD é o desvio de comércio; $\mathrm{E}_{\mathrm{s}}$, a elasticidade de substituição; $\mathrm{P}$, o preço; $k$, preço e importações referentes a parceiros (países beneficiados com as reduções tarifárias); e K, preço e importações referentes a não-parceiros.

A utilização da expressão (2) apresenta a desvantagem de necessitar de uma estimativa para a elasticidade de substituição $\left(E_{s}\right)$. Para os propósitos deste trabalho foi utilizado $E_{s}=-2,5$, indicando maior grau de substitutibilidade entre os produtos comercializados.

Quanto ao grau de desagregação das simulações, deve-se trabalhar inicialmente com setores desagregados, e os resultados devem ser consolidados no fim. Uma pré-agregação tarifária, antes de as fórmulas de criação e desvio de comércio serem aplicadas, ocasionaria um viés nas quantificações, mesmo nos casos de reduções tarifárias lineares.

\subsection{Parâmetros utilizados e fonte de dados}

Os dados referentes às importações (CIF - Cost Insurance Freight) e exportações (FOB - Free on Board) do Brasil e dos outros países do Mercosul, total e por país de origem, em mil dólares, no período de 2000 a 2005, foram coletados no Ministério do Desenvolvimento, Indústria e Comércio Exterior, MDIC (pelo sistema Alice Web) e no site da Associação Latino-Americana de Integração, Aladi 
(www.aladi.org). Os valores referentes às exportações e às importações da União Européia, total e por país de origem, em mil Euros, no período de 2000 a 2005, foram coletados na base de dados da Comissão Européia (Eurostat), por meio do site Export Helpdesk (www.exporthelp.europa.eu/). Esses valores foram convertidos em dólares americanos pela taxa média de câmbio Euro/US\$, divulgada pelo Fundo Monetário Internacional (FMI).

Para o cálculo de criação e desvio de comércio foram utilizados dados anuais por capítulo do Sistema Harmonizado de Classificação de Comércio (SH) Capítulo 01 a 24 -, classificados a dois dígitos na Nomenclatura Comum do Mercosul (NCM), relativos aos anos de 2004 e 2005. As tarifas consideradas referem-se às Most Favoured Nations (MFN) impostas pela UE e foram extraídas de Freitas e Costa (2005), tendo sido calculadas pela World Trade Organization (WTO) no exercício de 2002. As elasticidades de importação da União Européia correspondem às elasticidades médias referentes aos principais países europeus e estão disponíveis na base de dados do World Bank.

\section{Resultados e discussão}

\subsection{Criação e desvio de comércio para o setor agroexportador brasileiro}

As exportações totais brasileiras, em 2005, atingiram cerca de US\$ 118,4 bilhões, enquanto as importações alcançaram US\$ 73,6 bilhões. Nesse ano, a UE foi o principal parceiro comercial do Brasil, tendo importado US\$ 26,6 bilhões e exportado US\$ 18,2 bilhões, que corresponderam, respectivamente, a 22,5\% e $24,7 \%$ do comércio brasileiro total.

No que se refere ao comércio agrícola, as exportações brasileiras com destino aos países europeus têm importância destacada. Em 2005, as exportações desse segmento alcançaram cerca de US\$ 11 bilhões (Tabela 2).

Tabela 2. Exportações agrícolas brasileiras para a União Européia em 2005, por capítulo do Sistema Harmonizado (SH), em 1.000 US\$, e a participação nas exportações agrícolas brasileiras

\begin{tabular}{llrrr}
\hline \multirow{2}{*}{ Capítulo } & Descrição do capítulo & $\begin{array}{r}\text { Tarifa } \\
(\%)\end{array}$ & $\begin{array}{r}\text { Valor } \\
\text { exportado }\end{array}$ & $\begin{array}{r}\text { Participação } \\
(\%)\end{array}$ \\
\hline 01 & Animais vivos. & 20,60 & 633 & 0,01 \\
02 & Carnes e miudezas, comestíveis. & 28,30 & 1.540 .195 & 13,97 \\
03 & Peixes e crustáceos, moluscos e outros. & 10,87 & 220.392 & 2,00 \\
04 & Leite e laticínios, ovos, mel natural. & 38,40 & 17.286 & 0,16 \\
05 & Outros produtos de origem animal. & 0,20 & 77.834 & 0,71 \\
\hline
\end{tabular}


Tabela 2. Continuação.

\begin{tabular}{llrrr}
\hline \multirow{2}{*}{ Capítulo } & Descrição do capítulo & $\begin{array}{r}\text { Tarifa } \\
(\%)\end{array}$ & $\begin{array}{r}\text { Valor } \\
\text { exportado }\end{array}$ & $\begin{array}{r}\text { Participação } \\
(\%)\end{array}$ \\
\hline 06 & Plantas vivas e produtos de floricultura. & 6,00 & 17.007 & 0,15 \\
07 & Produtos hortícolas, plantas e raízes. & 12,70 & 6.712 & 0,06 \\
08 & Frutas, cascas de cítricos e de melões. & 9,00 & 408.975 & 3,71 \\
09 & Café, chá, mate e especiarias. & 3,10 & 1.576 .029 & 14,30 \\
10 & Cereais. & 39,20 & 16.784 & 0,15 \\
11 & Produtos da indústria de moagem. & 22,20 & 2.374 & 0,02 \\
12 & Sementes e frutos oleaginosos e grãos. & 1,80 & 2.656 .538 & 24,10 \\
13 & Gomas, resinas e outros sucos. & 2,20 & 12.048 & 0,11 \\
14 & Matérias para trançaria e outros. & 0,00 & 1.028 & 0,01 \\
15 & Gorduras, óleos e ceras animais e vegetais. & 8,90 & 192.934 & 1,75 \\
16 & Preparações de carne, de peixes e outros. & 18,50 & 472.814 & 4,29 \\
17 & Açúcares e produtos de confeitaria. & 21,40 & 57.889 & 0,53 \\
18 & Cacau e suas preparações. & 11,80 & 48.534 & 0,44 \\
19 & Preparações à base de cereais e farinhas. & 16,40 & 3.664 & 0,03 \\
20 & Preparações de produtos hortícolas e de frutas. & 20,60 & 745.639 & 6,77 \\
21 & Preparações alimentícias diversas. & 9,60 & 106.653 & 0,97 \\
22 & Bebidas, líquidos alcoólicos e vinagres. & 5,50 & 174.229 & 1,58 \\
23 & Resíduos das indústrias alimentares. & 7,00 & 2.026 .700 & 18,39 \\
24 & Fumo e seus sucedâneos. & 18,30 & 638.356 & 5,79 \\
\hline Total das exportações agrícolas & & $\mathbf{1 1 . 0 2 1 . 2 4 7}$ & $\mathbf{1 0 0 , 0 0}$ \\
\hline
\end{tabular}

Fonte: MDIC/Secex (2005), elaboração do autor.

Nas exportações de bens agrícolas, dentre os principais capítulos, destacam-se os dos semimanufaturados de base agropecuária intensivos em trabalho, como carne, suco de laranja e fumo, e os que englobam produtos primários, como soja e café.

Dada a importância dos produtos agrícolas na pauta de exportação brasileira para a União Européia e as altas taxas tarifárias impostas a esses produtos pelo bloco, procurou-se avaliar, em termos de ganhos, quais seriam as conseqüências do estabelecimento de um acordo de livre comércio entre o Mercosul e UE. Essa questão tornou-se ainda mais importante para o Brasil após a recente incorporação dos dez novos membros ao bloco, que possuem como força exportadora o setor agrícola.

Nesse sentido, foram simulados dois cenários alternativos de integração entre Mercosul e UE: 
- Cenário I: numa perspectiva de integração mais otimista para o Brasil, os cálculos de criação e desvio de comércio foram feitos supondo-se uma redução de $100 \%$ nas tarifas vigentes para os produtos agrícolas.

- Cenário II: com o intuito de mensurar o impacto proveniente da proteção que a UE oferece aos países pertencentes ao bloco, foi simulado um cenário de integração, relacionando os produtos que possuem maior importância dentro do comércio intrabloco e maior proteção tarifária. Ou seja, um produto que tem grande representatividade no comércio entre os 25 países da UE e possui alta tarifa para os parceiros de fora da UE pode ser considerado estratégico para os países europeus. Nesse cenário, os produtos considerados estratégicos para a UE são exceções no acordo, ou seja, suas tarifas permaneceram inalteradas. Para o restante dos produtos, supôs-se uma redução de $100 \%$ nas tarifas.

Optou-se por calcular a criação e o desvio de comércio, tomando como base a média importada em 2004 e 2005, uma vez que a incorporação dos dez novos membros pela UE ocorreu em 2004, embora as negociações com o Mercosul tenham se iniciado em 1998.

\subsubsection{Cenário I - redução tarifária de $100 \%$}

\section{Criação de Comércio}

A criação de comércio implica a possibilidade de substituição da produção doméstica, menos eficiente, pela importação procedente de um parceiro comercial, mais competitivo devido à ausência de barreiras. Na Tabela 3, são apresentados os resultados da estimativa de criação de comércio para as exportações agrícolas brasileiras em um cenário de ausência de barreiras comerciais impostas pela UE.

Tabela 3. Criação de comércio para as exportações agrícolas brasileiras, por capítulo do SH, em 1.000 US\$

\begin{tabular}{llrrr}
\hline $\begin{array}{l}\text { Capítulo } \\
\text { do SH }\end{array}$ & Descrição do capítulo & $\begin{array}{r}\text { Exportação } \\
\text { (média 04/05) }\end{array}$ & $\begin{array}{r}\text { Criação de } \\
\text { comércio }\end{array}$ & $\begin{array}{r}\text { Ganho } \\
\mathbf{( \% )}\end{array}$ \\
\hline 01 & Animais vivos. & 462 & 65 & 14,09 \\
02 & Carnes e miudezas, comestíveis. & 1.506 .139 & 332.620 & 22,08 \\
03 & Peixes e crustáceos, moluscos e outros. & 216.250 & 21.454 & 9,92 \\
04 & Leite e laticínios, ovos, mel natural. & 26.810 & 7.172 & 26,75 \\
05 & Outros produtos de origem animal. & 75.023 & 221 & 0,29 \\
06 & Plantas vivas e produtos de floricultura. & 16.616 & 926 & 5,57 \\
07 & Produtos hortícolas, plantas e raízes. & 6.057 & 792 & 13,07 \\
\hline
\end{tabular}


Tabela 3. Continuação.

\begin{tabular}{|c|c|c|c|c|}
\hline $\begin{array}{l}\text { Capítulo } \\
\text { do SH }\end{array}$ & Descrição do capítulo & $\begin{array}{r}\text { Exportação } \\
\text { (média 04/05) }\end{array}$ & $\begin{array}{l}\text { Criação de } \\
\text { comércio }\end{array}$ & $\begin{array}{r}\text { Ganho } \\
(\%)\end{array}$ \\
\hline 08 & Frutas, cascas de cítricos e de melões. & 373.128 & 30.122 & 8,07 \\
\hline 09 & Café, chá, mate e especiarias. & 1.354 .853 & 44.985 & 3,32 \\
\hline 10 & Cereais. & 134.817 & 62.876 & 46,64 \\
\hline 11 & Produtos da indústria de moagem. & 2.244 & 406 & 18,08 \\
\hline 12 & Sementes e frutos oleaginosos e grãos. & 2.616 .467 & 54.326 & 2,08 \\
\hline 13 & Gomas, resinas e outros sucos. & 10.695 & 224 & 2,10 \\
\hline 14 & Matérias para trançaria e outros. & 808 & 0 & 0,00 \\
\hline 15 & Gorduras, óleos e ceras animais e vegetais. & 138.330 & 10.335 & 7,47 \\
\hline 16 & Preparações de carne, de peixes e outros. & 372.802 & 59.944 & 16,08 \\
\hline 17 & Açúcares e produtos de confeitaria. & 52.995 & 28.617 & 54,00 \\
\hline 18 & Cacau e suas preparações. & 41.780 & 1.272 & 3,05 \\
\hline 19 & Preparações à base de cereais e farinhas. & 3.343 & 1.072 & 32,08 \\
\hline 20 & Preparações de hortícolas e de frutas. & 770.267 & 189.511 & 24,60 \\
\hline 21 & Preparações alimentícias diversas. & 93.086 & 13.956 & 14,99 \\
\hline 22 & Bebidas, líquidos alcoólicos e vinagres. & 136.720 & 7.332 & 5,36 \\
\hline 23 & Resíduos das indústrias alimentares. & 2.230 .341 & 184.535 & 8,27 \\
\hline 24 & Fumo e seus sucedâneos. & 567.578 & 187.105 & 32,97 \\
\hline Total & & 10.747 .610 & 1.239 .868 & 11,54 \\
\hline
\end{tabular}

Fonte: Resultados da pesquisa.

Foram observados ganhos expressivos de comércio para a maioria dos capítulos das exportações agrícolas brasileiras. Supondo-se o estabelecimento de uma zona de livre comércio entre o Mercosul e União Européia (redução de 100\% nas tarifas vigentes), o modelo adotado indicou que as exportações brasileiras com destino àquele bloco teriam incremento total da ordem de $11,54 \%$ (US\$ $1.239,87$ milhões).

Em termos absolutos, o Capítulo 02 (Carnes e miudezas, comestíveis) apresentou maior ganho com a eliminação das barreiras comerciais, US\$ 332,6 milhões, cerca de $26,8 \%$ do ganho total. Outros capítulos também apresentaram ganhos significativos de exportação, valendo destacar os Capítulos 20 (Preparações de produtos hortícolas e de frutas), com US\$189,5 milhões (15,28\%); 24 (Fumo e seus sucedâneos), com US\$187,1 milhões (15,09\%); e 23 (Resíduos das indústrias alimentares), com US\$184,5 milhões $(14,88 \%)$.

O incremento total nas exportações desses capítulos (US\$ 893,7 milhões) deve-se principalmente ao grande volume de exportação, além das altas taxas tarifárias incidentes sobre eles. Num contexto de livre comércio, devido ao grande volume comercializado, a eliminação das tarifas provocou grande 
incentivo à criação de comércio, representando, especificamente, 72,09\% do ganho total nas exportações. Esse resultado pode ser interpretado como um aspecto positivo da liberalização comercial, dada a grande importância desses produtos para a pauta agroexportadora brasileira. Em 2005, somente as exportações referentes a esses capítulos foram responsáveis por $44,92 \%$ das exportações agrícolas brasileiras para a UE, totalizando aproximadamente US\$ 5 bilhões.

O Capítulo 17 (Açúcares e produtos de confeitaria) destacou-se com o melhor resultado em termos de ganhos proporcionais, aumentando suas exportações em 54\%. Os Capítulos 10 (Cereais), com 46,64\%, 24 (Fumo e seus sucedâneos), com $32,97 \%$, e 19 (Preparações à base de cereais e farinhas), com 32,08\%, completam o grupo dos produtos que obtiveram melhores desempenhos proporcionais.

Esse desempenho alcançado, além de refletir os ganhos ocasionados pela eliminação das tarifas, foi influenciado principalmente pela magnitude das elasticidades de importação em cada capítulo. Assim, uma redução nos preços provoca o aumento proporcionalmente maior na quantidade demandada, a despeito da baixa importância desses produtos $(17,10,24$ e 19) para o setor agroexportador brasileiro, que juntos representaram, em 2005, cerca de 6,5\% da pauta agrícola exportada para a UE.

\section{Desvio de Comércio}

O desvio de comércio indica a possibilidade de substituição de um produtor externo, considerado mais eficiente, pelo parceiro comercial menos competitivo, o que resulta na redução da eficiência mundial e, conseqüentemente, no bem-estar. Contudo, se o parceiro que recebe tratamento preferencial for o fornecedor mais eficiente, não haverá desvio de comércio.

Tendo em vista o objetivo do presente trabalho - analisar o desempenho do setor agroexportador brasileiro -, o desvio de comércio deve ser interpretado de maneira diferenciada. Nesse caso específico, o desvio significa um aumento nas exportações brasileiras, ocasionado pelo redirecionamento de parte das importações da UE dos países não-parceiros ao acordo Mercosul/UE para o Brasil. Entretanto, quanto mais eficiente for o Brasil na produção desses bens, menores serão os valores do desvio de comércio.

A hipótese adotada para o cálculo é de que, depois de firmado o acordo de livre comércio, as tarifas para os parceiros do bloco são zeradas, enquanto aquelas referentes aos não-parceiros permanecem inalteradas. A estimativa de desvio de comércio requer levar em consideração a elasticidade de substituição dos produtos entre os países, e maior elasticidade implica maior desvio de comércio. Neste trabalho foi considerada a pressuposição $E_{s}=-2,5$, admitindo maior grau de substitutibilidade dos produtos entre os países. Os resultados obtidos encontram-se na Tabela 4. 
Segundo os resultados, o aumento final nas exportações desses produtos foi de US\$ 376,68 milhões, aproximadamente 3,5\% do total da pauta agrícola exportada para a UE.

Tabela 4. Desvio de comércio para as exportações agrícolas brasileiras, por capítulo do SH, em 1.000 US\$

\begin{tabular}{|c|c|c|c|c|}
\hline $\begin{array}{l}\text { Capítulo } \\
\text { do SH }\end{array}$ & Descrição do capítulo & $\begin{array}{r}\text { Exportação } \\
\text { (média 04/05) }\end{array}$ & $\begin{array}{r}\text { Desvio de } \\
\text { comércio }\end{array}$ & $\begin{array}{r}\text { Ganho } \\
(\%) \\
\end{array}$ \\
\hline 01 & Animais vivos. & 462 & 42 & 9,04 \\
\hline 02 & Carnes e miudezas, comestíveis. & 1.506 .139 & 28.569 & 1,90 \\
\hline 03 & Peixes e crustáceos, moluscos e outros. & 216.250 & 25.297 & 11,70 \\
\hline 04 & Leite e laticínios, ovos, mel natural. & 26.810 & 502 & 1,87 \\
\hline 05 & Outros produtos de origem animal. & 75.023 & 199 & 0,27 \\
\hline 06 & Plantas vivas e produtos de floricultura. & 16.616 & 393 & 2,37 \\
\hline 07 & Produtos hortícolas, plantas e raízes. & 6.057 & 330 & 5,44 \\
\hline 08 & Frutas, cascas de cítricos e de melões. & 373.128 & 41.023 & 10,99 \\
\hline 09 & Café, chá, mate e especiarias. & 1.354 .853 & 46.151 & 3,41 \\
\hline 10 & Cereais. & 134.817 & 16.290 & 12,08 \\
\hline 11 & Produtos da indústria de moagem. & 2.244 & 28 & 1,27 \\
\hline 12 & Sementes e frutos oleaginosos e grãos. & 2.616 .467 & 32.992 & 1,26 \\
\hline 13 & Gomas, resinas e outros sucos. & 10.695 & 283 & 2,65 \\
\hline 14 & Matérias para trançaria e outros. & 808 & 0 & 0,00 \\
\hline 15 & Gorduras, óleos e ceras animais e vegetais. & 138.330 & 6.165 & 4,46 \\
\hline 16 & Preparações de carne, de peixes e outros. & 372.802 & 51.883 & 13,92 \\
\hline 17 & Açúcares e produtos de confeitaria. & 52.995 & 4.563 & 8,61 \\
\hline 18 & Cacau e suas preparações. & 41.780 & 3.111 & 7,45 \\
\hline 19 & Preparações à base de cereais e farinhas. & 3.343 & 50 & 1,49 \\
\hline 20 & Preparações de hortícolas e de frutas. & 770.267 & 49.828 & 6,47 \\
\hline 21 & Preparações alimentícias diversas. & 93.086 & 1.765 & 1,90 \\
\hline 22 & Bebidas, líquidos alcoólicos e vinagres. & 136.720 & 1.730 & 1,27 \\
\hline 23 & Resíduos das indústrias alimentares. & 2.230 .341 & 47.301 & 2,12 \\
\hline 24 & Fumo e seus sucedâneos. & 567.578 & 18.189 & 3,20 \\
\hline Total & & 10.747 .610 & 376.684 & 3,50 \\
\hline
\end{tabular}

Fonte: Resultados da pesquisa.

De maneira geral, as estimativas obtidas para a criação de comércio foram, na maioria das vezes, superiores àquelas para o desvio de comércio. Apenas os Capítulos 03 (Peixes e crustáceos, moluscos e outros), 08 (Frutas, cascas de cítricos e de melões), 09 (Café, chá, mate e especiarias), 13 (Gomas, resinas e outros sucos) e 18 (Cacau e suas preparações) apresentaram estimativas de desvio de comércio superiores à criação de comércio. 
Esses resultados comprovaram a eficiência na produção e competitividade dos produtos agropecuários brasileiros no mercado mundial. Segundo Cypriano e Teixeira (2003), os países do Mercosul são mais competitivos nos produtos do agronegócio e menos nos produtos manufaturados. Waquil et al. (2004) também corroboram esses resultados, concluindo que as cadeias brasileiras de soja e derivados, suco de laranja, fumo, frango, carne bovina, açúcar e café, no período de 1991 a 2001, possuíam maior eficiência na produção e na comercialização do que os demais países atuantes no mercado internacional.

\section{Efeito Total}

Os ganhos para o setor agroexportador brasileiro foram provenientes de duas origens: pela criação de comércio, em que a UE substituiu sua produção doméstica, menos eficiente, pela importação procedente do Brasil, mais competitivo devido à ausência de tarifas; e pelo desvio de comércio, que provocou o redirecionamento de parte das importações da UE dos países não-parceiros ao acordo Mercosul/UE para o Brasil.

Assim, é possível analisar o efeito total proveniente do estabelecimento de um ambiente livre de tarifas entre Brasil e UE, somando-se as estimativas de criação e desvio de comércio (Tabela 5).

Tabela 5. Efeito total da integração, por capítulo do SH, em 1.000 US\$

\begin{tabular}{llrrr}
\hline $\begin{array}{l}\text { Capítulo } \\
\text { do SH }\end{array}$ & Descrição do capítulo & $\begin{array}{r}\text { Exportação } \\
\text { (média 04/05) }\end{array}$ & $\begin{array}{r}\text { Efeito } \\
\text { total }\end{array}$ & $\begin{array}{r}\text { Ganho } \\
\mathbf{( \% )}\end{array}$ \\
\hline 01 & Animais vivos. & 462 & 107 & 23,13 \\
02 & Carnes e miudezas, comestíveis. & 1.506 .139 & 361.190 & 23,98 \\
03 & Peixes e crustáceos, moluscos e outros. & 216.250 & 46.751 & 21,62 \\
04 & Leite e laticínios, ovos, mel natural. & 26.810 & 7.673 & 28,62 \\
05 & Outros produtos de origem animal. & 75.023 & 420 & 0,56 \\
06 & Plantas vivas e produtos de floricultura. & 16.616 & 1.319 & 7,94 \\
07 & Produtos hortícolas, plantas e raízes. & 6.057 & 1.121 & 18,51 \\
08 & Frutas, cascas de cítricos e de melóes. & 373.128 & 71.144 & 19,07 \\
09 & Café, chá, mate e especiarias. & 1.354 .853 & 91.136 & 6,73 \\
10 & Cereais. & 134.817 & 79.166 & 58,72 \\
11 & Produtos da indústria de moagem. & 2.244 & 434 & 19,35 \\
12 & Sementes e frutos oleaginosos e grãos. & 2.616 .467 & 87.318 & 3,34 \\
13 & Gomas, resinas e outros sucos. & 10.695 & 507 & 4,74 \\
14 & Matérias para trançaria e outros. & 808 & 0 & 0,00 \\
15 & Gorduras, óleos e ceras animais e vegetais. & 138.330 & 16.500 & 11,93 \\
16 & Preparações de carne, de peixes e outros. & 372.802 & 111.827 & 30,00 \\
17 & Açúcares e produtos de confeitaria. & 52.995 & 33.180 & 62,61 \\
\hline
\end{tabular}


Tabela 5. Continuação.

\begin{tabular}{llrrr}
\hline $\begin{array}{l}\text { Capítulo } \\
\text { do SH }\end{array}$ & Descrição do capítulo & $\begin{array}{r}\text { Exportação } \\
\text { (média 04/05) }\end{array}$ & $\begin{array}{r}\text { Efeito } \\
\text { total }\end{array}$ & $\begin{array}{r}\text { Ganho } \\
(\mathbf{\%})\end{array}$ \\
\hline 18 & Cacau e suas preparações. & 41.780 & 4.383 & 10,49 \\
19 & Preparações à base de cereais e farinhas. & 3.343 & 1.122 & 33,57 \\
20 & Preparações de hortícolas e de frutas. & 770.267 & 239.340 & 31,07 \\
21 & Preparações alimentícias diversas. & 93.086 & 15.722 & 16,89 \\
22 & Bebidas, líquidos alcoólicos e vinagres. & 136.720 & 9.062 & 6,63 \\
23 & Resíduos das indústrias alimentares. & 2.230 .341 & 231.836 & 10,39 \\
24 & Fumo e seus sucedâneos. & 567.578 & 205.294 & 36,17 \\
\hline Total & & $\mathbf{1 0 . 7 4 7 . 6 1 0}$ & $\mathbf{1 . 6 1 6 . 5 5 2}$ & $\mathbf{1 5 , 0 4}$ \\
\hline
\end{tabular}

Fonte: Resultados da pesquisa.

A implantação de uma área de livre comércio entre Mercosul e União Européia traria ganhos significativos para as exportações do agronegócio brasileiro para a UE. De acordo com os resultados, os maiores ganhos absolutos na exportação foram obtidos pelos produtos que compõem os Capítulos 02 (Carnes e miudezas, comestíveis), com US\$316,2 milhões (22,34\%), 20 (Preparações de produtos hortícolas e de frutas), com US\$239,34 milhões (14,81\%), 23 (Resíduos das indústrias alimentares), com US\$231,83 milhões (14,34\%), e 24 (Fumo e seus sucedâneos), com US\$205,3 milhões (12,7\%). Vale destacar que as exportações desses produtos para a UE totalizaram, em 2005, quase US\$ 5 bilhões, o que equivale a $45 \%$ do comercializado no segmento agrícola com o bloco.

Por outro lado, os maiores ganhos em termos proporcionais foram obtidos pelas exportações dos produtos que compõem os Capítulos 17 (Açúcares e produtos de confeitaria), de 62,61\%, 10 (Cereais), (58,72\%), 24 (Fumo e seus sucedâneos), $(36,17 \%), 19$ (Preparações à base de cereais e farinhas), (33,57\%), 20 (Preparações de produtos hortícolas e de frutas), (31,07\%), 16 (Preparações de carne, de peixes e outros), (30\%), e 04 (Leite e laticínios, ovos de aves, mel natural), (28,62\%). Contudo, apesar do bom desempenho alcançado, esses produtos são pouco representativos para as exportações do agronegócio brasileiro com destino à UE, em 2005, corresponderam a 17,72\% das exportaçóes desse segmento para o bloco.

Em síntese, se o acordo Mercosul/UE fosse estabelecido com eliminação total das tarifas para os produtos agrícolas (cenário I), segundo o modelo, os ganhos de exportação do Brasil para esse segmento com a criação de comércio seriam de US\$ $1.239,87$ milhões, e, com o desvio de comércio, considerando $E_{s}=-2,5$, alcançariam US\$ 376,68 milhões, totalizando aproximadamente US\$ 1.616 milhões, $15,04 \%$ do valor médio exportado no período.

Os resultados encontrados confirmam as perspectivas de pesquisas anteriores que destacaram o potencial do setor agroexportador brasileiro de forma semelhante, ou seja, pressupondo eliminação tarifária ou tarifa zero. Castilho (2001), a partir de um modelo gravitacional, buscou auferir os ganhos de 
um acordo Mercosul/UE, constatando que, entre os produtos com maior potencial de expansão das exportações, figuram diversos produtos de origem agrícola, que têm suas importações sensíveis às barreiras comerciais, fazendo face à elevada proteção, e representam ainda um importante volume de exportações.

Decreux e Guérin (20015 apud CASTILHO, 2002) utilizaram o modelo GTAP para medir o impacto de três simulações: a formação da Alca, o acordo Mercosul/UE e a realização simultânea dos dois acordos. Este modelo introduziu aspectos dinâmicos ao simular resultados ao longo de um período e não somente em uma rodada. A redução das barreiras foi feita progressivamente ao longo de 15 anos, conforme a proposição de liberalização feita pela UE ao Mercosul, e os resultados foram sendo acumulados ao longo desse período. De acordo com os autores, as economias do Mercosul obteriam maiores ganhos - tanto em termos de aumento do comércio quanto em termos de crescimento econômico e aumento de salários - no caso de um acordo com a UE. As exportações do Mercosul que apresentaram maior crescimento se concentraram em produtos de origem agrícola (cereais, leite e açúcar, outros produtos agrícolas e, principalmente, carnes).

A partir dos anos de 2000, outros trabalhos, com o intuito de avaliar os ganhos brasileiros diante da perspectiva de integração Mercosul/UE, confirmam a existência de significativos ganhos para o setor agroexportador brasileiro, apresentando diferenças nas estimativas obtidas, que provavelmente foram influenciadas pelos diferentes parâmetros utilizados para as elasticidades de importação, elasticidades de substituição e tarifas. Por meio de um modelo de equilíbrio parcial, De Negri e Arbache (2003) buscaram identificar as linhas tarifárias restringidas por tarifas específicas no mercado europeu e quantificar o impacto da sua eliminação em termos do aumento das exportações totais do Brasil para esse mercado. Em um cenário de criação de uma zona de livre comércio, em que todas as tarifas fossem zeradas, as estimativas indicaram aumento das exportações brasileiras para o mercado europeu no montante de U\$ 691 milhões, o que equivale a um aumento de 4,62\% nas exportações, se considerada a média do valor exportado entre 1998 e 2000.

Utilizando também um modelo de equilíbrio parcial, Kume et al. (2004) avaliaram o impacto das ofertas de liberalização de comércio do Mercosul e da UE sobre o comércio exterior brasileiro. Segundo os autores, os ganhos para o Brasil, resultantes da criação e do desvio de comércio devido à eliminação das tarifas de importação de manufaturas por parte da UE (à exceção de produtos com preferência tarifária fixa), bem como os gerados pela concessão de quotas tarifárias para produtos processados da agroindústria, atingiram um total de US\$ 903 milhões, dos quais US\$ 709 milhões foram provenientes da agropecuária.

${ }^{5}$ DECREUX, Y.; GUÉRIN, J. L. Mercosur: free-trade area with the EU or with the Americas? Some lessons from the model Mirage. Artigo apresentado no Seminário Impacts of Trade Liberalization Agreements on Latin America and the Caribbean. Washington: CEPII e BID (orgs.), Nov. 2001. 


\subsubsection{Cenário II - cenário estratégico}

Neste cenário, define-se um capítulo de exportação como estratégico para a UE com base em duas características: a importância relativa dos produtos para as importações intra-UE e a incidência tarifária. Assim, os capítulos foram classificados como estratégicos quando representavam grande parcela das importações intrabloco e eram protegidos por altas tarifas.

Como as altas tarifas têm como objetivo principal proteger os produtores internos da concorrência externa, as perdas para os países seriam maiores à medida que fossem eliminadas as tarifas incidentes sobre os produtos com maior volume comercializado dentro do próprio bloco. Num ambiente livre de tarifas, os parceiros intrabloco seriam substituídos por estrangeiros mais competitivos. No caso da UE, segundo dados da Eurostat (2006), a maior parte das importações de produtos agrícolas tem como origem os próprios países europeus. Em 2005, o comércio intrabloco desse segmento representou $72,93 \%$ das importações totais.

A Tabela 6 apresenta a importância relativa dos produtos aglomerados em capítulos e o nível da tarifa incidente sobre eles.

Tabela 6. Importações intrabloco da UE no ano de 2005, por capítulo do SH, em 1.000 US\$, e tarifa imposta para os não-parceiros ao bloco

\begin{tabular}{llrrr}
\hline $\begin{array}{l}\text { Capítulo } \\
\text { do SH }\end{array}$ & Descrição do capítulo & $\begin{array}{r}\text { Importações } \\
\text { intrabloco }\end{array}$ & $\begin{array}{r}\text { Tarifa } \\
\mathbf{( \% )}\end{array}$ & $\begin{array}{r}\text { Participáção } \\
\mathbf{( \% )}\end{array}$ \\
\hline 01 & Animais vivos. & 6.086 .047 & 20,60 & 2,44 \\
02 & Carnes e miudezas, comestíveis. & 26.253 .660 & 28,30 & 10,53 \\
03 & Peixes e crustáceos, moluscos e outros. & 12.317 .026 & 10,87 & 4,94 \\
04 & Leite e laticínios, ovos, mel natural. & 25.007 .346 & 38,40 & 10,03 \\
05 & Outros produtos de origem animal. & 1.339 .031 & 0,20 & 0,54 \\
06 & Plantas vivas e produtos de floricultura. & 8.346 .107 & 6,00 & 3,35 \\
07 & Produtos hortícolas, plantas e raízes. & 15.342 .967 & 12,70 & 6,16 \\
08 & Frutas, cascas de cítricos e de melões. & 17.022 .680 & 9,00 & 6,83 \\
09 & Café, chá, mate e especiarias. & 2.858 .967 & 3,10 & 1,15 \\
10 & Cereais. & 8.288 .051 & 39,20 & 3,32 \\
11 & Produtos da indústria de moagem. & 2.434 .139 & 22,20 & 0,98 \\
12 & Sementes e frutos oleaginosos e grãos. & 4.553 .260 & 1,80 & 1,83 \\
13 & Gomas, resinas e outros sucos. & 908.273 & 2,20 & 0,36 \\
14 & Matérias para trançaria e outros. & 90.014 & 0,00 & 0,04 \\
15 & Gorduras, óleos e ceras animais e vegetais. & 9.891 .182 & 8,90 & 3,97 \\
16 & Preparações de carne, de peixes e outros. & 7.889 .443 & 18,50 & 3,17 \\
17 & Açúcares e produtos de confeitaria. & 7.594 .999 & 21,40 & 3,05 \\
18 & Cacau e suas preparações. & 8.908 .533 & 11,80 & 3,57 \\
\hline
\end{tabular}


Tabela 6. Continuação.

\begin{tabular}{llrrr}
\hline $\begin{array}{l}\text { Capítulo } \\
\text { do SH }\end{array}$ & Descrição do capítulo & $\begin{array}{r}\text { Importações } \\
\text { intrabloco }\end{array}$ & $\begin{array}{r}\text { Tarifa } \\
\mathbf{( \% )}\end{array}$ & $\begin{array}{r}\text { Participáção } \\
\mathbf{( \% )}\end{array}$ \\
\hline 19 & Preparações à base de cereais e farinhas. & 14.472 .361 & 16,40 & 5,81 \\
20 & Preparações de hortícolas e de frutas. & 12.916 .164 & 20,60 & 5,18 \\
21 & Preparações alimentícias diversas. & 12.270 .565 & 9,60 & 4,92 \\
22 & Bebidas, líquidos alcoólicos e vinagres. & 23.751 .211 & 5,50 & 9,53 \\
23 & Resíduos das indústrias alimentares. & 9.356 .473 & 7,00 & 3,75 \\
24 & Fumo e seus sucedâneos. & 11.372 .907 & 18,30 & 4,56 \\
\hline Total & $\mathbf{2 4 9 . 2 7 1 . 4 0 5}$ & & $\mathbf{1 0 0 , 0 0}$ \\
\hline Fonte: Resultados da pesquisa. & & &
\end{tabular}

Foram classificados como produtos com alta representatividade para a UE aqueles referentes aos Capítulos 02 (Carnes e miudezas, comestíveis), com 10,53\%, 04 (Leite e laticínios, ovos de aves, mel natural, 10,03\%, e 22 (Bebidas, líquidos alcoólicos e vinagres), 9,53\%. Já os produtos que compõem os Capítulos 08 (Frutas, cascas de cítricos e de melões), com 6,83\%), 07 (Produtos hortícolas, plantas, raízes e tubérculos comestíveis), 6,16\%, 19 (Preparações à base de cereais e farinhas), 5,81\%, 20 (Preparações de produtos hortícolas e de frutas), 5,18\%, 03 (Peixes e crustáceos, moluscos e outros), 4,94\%, 21 (Preparações alimentícias diversas), 4,92\% , e 24 (Fumo e seus sucedâneos), 4,56\%, foram classificados como tendo uma importância média para as importações intra-UE.

Quanto às tarifas incidentes, os produtos classificados com um alto nível de proteção foram aqueles referentes aos Capítulos 10 (Cereais), com 39,2\%, 04 (Leite e laticínios, ovos de aves, mel natural), 38,4\%, 02 (Carnes e miudezas, comestíveis), 28,3\%, 11 (Produtos da indústria de moagem, malte, amidos e féculas), 22,2\%, 17 (Açúcares e produtos de confeitaria), 21,4\%, 20 (Preparações de produtos hortícolas e de frutas), 20,6\%, 01 (Animais vivos), 20,6\%, 16 (Preparações de carne, de peixes e outros), 18,5\%, 24 (Fumo e seus sucedâneos), $18,3 \%$, e 19 (Preparações a base de cereais e farinhas), $16,4 \%$.

A partir do cruzamento desses dados, foram obtidos os Capítulos considerados estratégicos para a UE: 02 (Carnes e miudezas, comestíveis), 04 (Leite e laticínios, ovos de aves, mel natural), 19 (Preparações à base de cereais e farinhas), 20 (Preparações de produtos hortícolas e de frutas) e 24 (Fumo e seus sucedâneos).

Assim, nesse cenário de integração, o cálculo de criação e desvio de comércio foi realizado considerando que os produtos que compõem os cinco capítulos supracitados entrariam na lista de exceções do acordo, ou seja, não teriam nenhuma redução tarifária. Para os demais produtos, admitiu-se uma redução de $100 \%$ nas tarifas. 


\section{Criação de Comércio}

Supondo-se que o acordo de integração fosse firmado conforme as condições do cenário II, os ganhos provenientes da criação de comércio seriam aproximadamente $58 \%$ menores que os obtidos com a eliminação total das tarifas para todos os produtos (Tabela 7).

Tabela 7. Criação de comércio para as exportações agrícolas brasileiras, por capítulo do SH, em 1.000 US\$

\begin{tabular}{llrrr}
\hline $\begin{array}{l}\text { Capítulo } \\
\text { do SH }\end{array}$ & Descrição do capítulo & $\begin{array}{r}\text { Exportação } \\
\text { (média 04/05) }\end{array}$ & $\begin{array}{r}\text { Criação de } \\
\text { comércio }\end{array}$ & $\begin{array}{r}\text { Ganho } \\
\mathbf{( \% )}\end{array}$ \\
\hline 01 & Animais vivos. & 462 & 65 & 14,09 \\
03 & Peixes e crustáceos, moluscos e outros. & 216.250 & 21.454 & 9,92 \\
05 & Outros produtos de origem animal. & 75.023 & 221 & 0,29 \\
06 & Plantas vivas e produtos de floricultura. & 16.616 & 926 & 5,57 \\
07 & Produtos hortícolas, plantas e raízes. & 6.057 & 792 & 13,07 \\
08 & Frutas, cascas de cítricos e de melões. & 373.128 & 30.122 & 8,07 \\
09 & Café, chá, mate e especiarias. & 1.354 .853 & 44.985 & 3,32 \\
10 & Cereais. & 134.817 & 62.876 & 46,64 \\
11 & Produtos da indústria de moagem. & 2.244 & 406 & 18,08 \\
12 & Sementes e frutos oleaginosos e grãos. & 2.616 .467 & 54.326 & 2,08 \\
13 & Gomas, resinas e outros sucos. & 10.695 & 224 & 2,10 \\
15 & Gorduras, óleos e ceras animais e vegetais. & 138.330 & 10.335 & 7,47 \\
16 & Preparações de carne, de peixes e outros. & 372.802 & 59.944 & 16,08 \\
17 & Açúcares e produtos de confeitaria. & 52.995 & 28.617 & 54,00 \\
18 & Cacau e suas preparações. & 41.780 & 1.272 & 3,05 \\
21 & Preparações alimentícias diversas. & 93.086 & 13.956 & 14,99 \\
22 & Bebidas, líquidos alcoólicos e vinagres. & 136.720 & 7.332 & 5,36 \\
23 & Resíduos das indústrias alimentares. & 2.230 .341 & 184.535 & 8,27 \\
\hline Total & & $\mathbf{1 0 . 7 4 7 . 6 1 0 *}$ & 522.388 & $\mathbf{4 , 8 6}$ \\
\hline Fonte: Resultados da pesquisa. & & & \\
${ }^{*}$ Corresponde ao total das exportações agrícolas com destino à UE. & & & \\
& & & & \\
& & &
\end{tabular}

Considerando-se a suposta lista de exceções da UE, a eliminação das tarifas referentes ao restante dos bens ocasionou incremento total da ordem de 4,86\% (US\$ 522,39 milhões).

Em termos absolutos, o Capítulo 23 (Resíduos das indústrias alimentares) apresentou maior ganho com a eliminação das barreiras comerciais, US\$184,53 milhões, cerca de 35,3\% do ganho total. Outros capítulos também mostraram ganhos significativos de exportação, valendo destacar os Capítulos 10 (Cereais), com US\$ 62,87 milhões (12,04\%), 16 (Preparações de carne, de peixes e outros), 
com US\$ 59,94 milhões $(11,48 \%)$ e 12 (Sementes e frutos oleaginosos, grãos, sementes), com US\$ 54,33 milhões (10,4\%).

Dentre os ganhos de exportação em termos proporcionais, destacou-se o Capítulo 17 (Açúcares e produtos de confeitaria), com o melhor resultado em termos de ganhos proporcionais, aumentando suas exportações em 54\%, e o Capítulo 10 (Cereais), com aumento de 46,64\% em suas exportações.

\section{Desvio de Comércio}

No cálculo do desvio de comércio, da mesma forma que no caso da criação de comércio, além de terem sido desconsiderados os capítulos da lista de exceções, supôs-se que, depois de firmado o acordo, as tarifas para os parceiros do bloco tivessem sido zeradas, enquanto àquelas referentes aos não-parceiros permaneceriam inalteradas (Tabela 8).

Tabela 8. Desvio de comércio, por capítulo do SH, em 1.000 US\$

\begin{tabular}{llrrr}
\hline $\begin{array}{l}\text { Capítulo } \\
\text { do SH }\end{array}$ & Descrição do capítulo & $\begin{array}{r}\text { Exportação } \\
\text { (média 04/05) }\end{array}$ & $\begin{array}{r}\text { Desvio de } \\
\text { comércio }\end{array}$ & $\begin{array}{r}\text { Ganho } \\
\mathbf{( \% )}\end{array}$ \\
\hline 01 & Animais vivos. & 462 & 42 & 9,04 \\
03 & Peixes e crustáceos, moluscos e outros. & 216.250 & 25.297 & 11,70 \\
05 & Outros produtos de origem animal. & 75.023 & 199 & 0,27 \\
06 & Plantas vivas e produtos de floricultura. & 16.616 & 393 & 2,37 \\
07 & Produtos hortícolas, plantas e raízes. & 6.057 & 330 & 5,44 \\
08 & Frutas, cascas de cítricos e de melões. & 373.128 & 41.023 & 10,99 \\
09 & Café, chá, mate e especiarias. & 1.354 .853 & 46.151 & 3,41 \\
10 & Cereais. & 134.817 & 16.290 & 12,08 \\
11 & Produtos da indústria de moagem. & 2.244 & 28 & 1,27 \\
12 & Sementes e frutos oleaginosos e grãos. & 2.616 .467 & 32.992 & 1,26 \\
13 & Gomas, resinas e outros sucos. & 10.695 & 283 & 2,65 \\
15 & Gorduras, óleos e ceras animais e vegetais. & 138.330 & 6.165 & 4,46 \\
16 & Preparações de carne, de peixes e outros. & 372.802 & 51.883 & 13,92 \\
17 & Açúcares e produtos de confeitaria. & 52.995 & 4.563 & 8,61 \\
18 & Cacau e suas preparações. & 41.780 & 3.111 & 7,45 \\
21 & Preparações alimentícias diversas. & 93.086 & 1.765 & 1,90 \\
22 & Bebidas, líquidos alcoólicos e vinagres. & 136.720 & 1.730 & 1,27 \\
23 & Resíduos das indústrias alimentares. & 2.230 .341 & 47.301 & 2,12 \\
\hline Total & & $\mathbf{1 0 . 7 4 7 . 6 1 0 *}$ & $\mathbf{2 7 9 . 5 4 6}$ & $\mathbf{2 , 6 0}$ \\
\hline
\end{tabular}

Fonte: Resultados da pesquisa.

Segundo os resultados, o aumento final nas exportações desses produtos foi de US\$ 279,55 milhões, aproximadamente 2,6\% do total da pauta agrícola exportada para a UE. 


\section{Efeito Total}

O ganho total das exportações no cenário II foi obtido somando-se as estimativas de criação e desvio de comércio (Tabela 9).

Tabela 9. Efeito total da integração, por capítulo do SH, em 1.000 US\$

\begin{tabular}{llrrr}
\hline $\begin{array}{l}\text { Capítulo } \\
\text { do SH }\end{array}$ & Descrição do capítulo & $\begin{array}{r}\text { Exportação } \\
\text { (média 04/05) }\end{array}$ & $\begin{array}{r}\text { Efeito } \\
\text { total }\end{array}$ & $\begin{array}{r}\text { Ganho } \\
\mathbf{( \% )}\end{array}$ \\
\hline 01 & Animais vivos. & 462 & 107 & 23,14 \\
03 & Peixes e crustáceos, moluscos e outros. & 216.250 & 46.751 & 21,62 \\
05 & Outros produtos de origem animal. & 75.023 & 420 & 0,56 \\
06 & Plantas vivas e produtos de floricultura. & 16.616 & 1.319 & 7,94 \\
07 & Produtos hortícolas, plantas e raízes. & 6.057 & 1.122 & 18,52 \\
08 & Frutas, cascas de cítricos e de melões. & 373.128 & 71.145 & 19,07 \\
09 & Café, chá, mate e especiarias. & 1.354 .853 & 91.136 & 6,73 \\
10 & Cereais. & 134.817 & 79.166 & 58,72 \\
11 & Produtos da indústria de moagem. & 2.244 & 434 & 19,34 \\
12 & Sementes e frutos oleaginosos e grãos. & 2.616 .467 & 87.318 & 3,34 \\
13 & Gomas, resinas e outros sucos. & 10.695 & 507 & 4,74 \\
15 & Gorduras, óleos e ceras animais e vegetais. & 138.330 & 16.500 & 11,93 \\
16 & Preparações de carne, de peixes e outros. & 372.802 & 111.827 & 30,00 \\
17 & Açúcares e produtos de confeitaria. & 52.995 & 33.180 & 62,61 \\
18 & Cacau e suas preparações. & 41.780 & 4.383 & 10,49 \\
21 & Preparaçóes alimentícias diversas. & 93.086 & 15.721 & 16,89 \\
22 & Bebidas, líquidos alcoólicos e vinagres. & 136.720 & 9.062 & 6,63 \\
23 & Resíduos das indústrias alimentares. & 2.230 .341 & 231.836 & 10,39 \\
\hline Total & & $\mathbf{1 0 . 7 4 7 . 6 1 0 *}$ & $\mathbf{8 0 1 . 9 3 4}$ & $\mathbf{7 , 4 6}$ \\
\hline Fonte: Resultados da pesquisa. & & & \\
${ }^{*}$ Corresponde ao total das exportações agrícolas com destino à UE. & & & \\
& & & & \\
\hline
\end{tabular}

Os resultados mostraram que, mesmo com a utilização de uma lista de exceções por parte da UE, a eliminação para o restante dos produtos trouxe um ganho não-desprezível para o agronegócio brasileiro. Os ganhos totais do setor agroexportador brasileiros atingiram US\$ 801,93 milhões, 7,46\% do valor médio exportado no período.

O maior ganho absoluto na exportação foi obtido pelos produtos que compõem o Capítulo 23 (Resíduos das indústrias alimentares), com US\$231,84 milhões $(28,91 \%)$. Por outro lado, os maiores ganhos em termos proporcionais foram obtidos pelas exportações dos produtos que compõem os Capítulos 17 (Açúcares e produtos de confeitaria), com 62,61\%, e 10 (Cereais), (58,72\%). 
Portanto, se o acordo de integração firmado entre Mercosul e UE estabelecesse a lista de exceções referente ao cenário II, os ganhos totais de comércio, supondo-se $\mathrm{E}_{\mathrm{s}}=-2,5$, seriam de US\$ 801,93 milhões. Os ganhos referentes à criação de comércio seriam de US\$ 522,39 milhões, e os referentes ao desvio de comércio, de US\$279,55 milhões.

\section{Conclusões}

Um acordo de integração comercial Mercosul/UE, responsável pela redução das barreiras tarifárias e não-tarifárias, pode resultar em ganhos comerciais para o Brasil. Contudo, a recente incorporação dos dez novos países do Leste Europeu ao bloco pode acrescentar maiores dificuldades de acesso do Mercosul ao mercado europeu, uma vez que a maioria dos novos membros tem a agricultura como força exportadora potencial.

Na perspectiva de constituição do acordo Mercosul/UE, com possibilidade de fortalecimento do comércio entre os blocos, o presente trabalho procurou estimar a criação e o desvio de comércio para o setor agroexportador brasileiro em dois cenários alternativos de integração. A criação e o desvio de comércio foram estimados, tomando-se como base a média importada em 2004 e 2005, uma vez que a incorporação dos dez novos membros pela UE ocorreu em 2004.

Os resultados para o cenário I, supondo redução de $100 \%$ nas tarifas vigentes para os produtos agrícolas, indicaram ganhos consideráveis para as exportações agrícolas brasileiras. Os ganhos totais de comércio para o Brasil ultrapassaram US\$ 1.616 milhões, 15,04\% do valor médio exportado nos anos de 2004 e 2005, sendo US\$1.239,87 milhões com a criação de comércio e US\$376,68 milhões com o desvio de comércio. Os maiores ganhos absolutos na exportação foram obtidos pelos produtos que compõem os Capítulos 02 (Carnes e miudezas, comestíveis), com US\$ 316,2 milhões (22,34\%), 20 (Preparações de produtos hortícolas e de frutas), com US\$239,34 milhões $(14,81 \%), 23$ (Resíduos das indústrias alimentares), com US\$231,83 milhões (14,34\%) e 24 (Fumo e seus sucedâneos), com US\$205,3 milhões (12,7\%). Vale destacar que as exportações desses produtos para UE totalizaram, em 2005, quase US\$ 5 bilhões, o que equivale a $45 \%$ do volume brasileiro comercializado no segmento agrícola. Por outro lado, os produtos exportados mais sensíveis às reduções nas tarifas foram os que compõem os Capítulos 17 (Açúcares e produtos de confeitaria), com 62,61\%, 10 (Cereais), com 58,72\%, 24 (Fumo e seus sucedâneos), com 36,17\%, 19 (Preparações à base de cereais e farinhas), 33,57\% , 20 (Preparações de produtos hortícolas e de frutas), 31,07\% , 16 (Preparações de carne, de peixes e outros), 30\%, e 04 (Leite e laticínios, ovos de aves, mel natural), 28,62\%. Contudo, apesar do significativo desempenho alcançado, esses produtos foram pouco 
representativos para as exportações do agronegócio brasileiro com destino à UE em 2005, tendo correspondido apenas a $17,72 \%$.

Com o intuito de mensurar o impacto proveniente da proteção comercial européia aos países pertencentes ao bloco, foi simulado um segundo cenário de integração, relacionando os produtos de maior importância para o comércio intrabloco e com maior proteção tarifária, ou seja, permaneceriam inalteradas as tarifas dos produtos considerados estratégicos para a UE, com possibilidade de serem incluídos nas listas de exceções no acordo Mercosul/UE. Para o restante dos produtos, supôs-se uma redução de $100 \%$ nas tarifas. Os resultados mostraram que, mesmo neste caso, ocorreriam ganhos não-desprezíveis para o agronegócio brasileiro. Os ganhos totais do setor agroexportador brasileiros atingiriam US\$ 801,93 milhões, 7,46\% do valor médio exportado no período. O maior ganho absoluto na exportação seria obtido pelos produtos que compõem o Capítulo 23 (Resíduos das indústrias alimentares), com US\$231,84 milhões $(28,91 \%)$. Por sua vez, os maiores ganhos em termos proporcionais ocorreriam nas exportações dos produtos que compõem os Capítulos 17 (Açúcares e produtos de confeitaria), com $62,61 \%$, e 10 (Cereais), com 58,72\%.

Os resultados obtidos para os dois níveis de redução tarifária confirmam as expectativas de que a integração Mercosul/UE ocasionaria ganhos comerciais significativos para o agronegócio brasileiro. É importante destacar que as estimativas de criação de comércio foram, na maior parte das simulações, superiores às de desvio de comércio, evidenciando a eficiência produtiva e competitividade do setor agroexportador brasileiro na economia mundial.

\section{Referências Bibliográficas}

CASTILHO, M.R. O acesso das exportaçóes do MERCOSUL ao mercado europeu. Texto para Discussão, n. 85. Rio de Janeiro: IPEA, 2001. 49p.

CASTILHO, M.R. Impactos de acordos comerciais sobre a economia brasileira: resenha dos trabalhos recentes. Rio de Janeiro: IPEA, 2002. 33p. (Texto para Discussão, n. 936).

CYPRIANO, L.A.; TEIXEIRA, E.C. Impactos da Alca e do Mercoeuro no agronegócio do MERCOSUL. Revista de Economia e Sociologia Rural, Brasília-DF, v. 41, n. 2, p. 217-240, 2003.

DE NEGRI, J.A.; ARBACHE, J.S. O impacto de um acordo entre MERCOSUL e a União européia sobre o potencial exportador brasileiro para o mercado europeu. Brasilia: IPEA, 2003. 34p. (Texto para discussão, n. 990). 
FREITAS, R. E.; COSTA C. C. Tarifas Agrícolas Européias: uma contribuição para a sua interpretação. Rio de Janeiro: IPEA, 2005. 40p. (Texto para Discussão, n. 1071)

Gabinete de Estatísticas da União Européia (EUROSTAT). 2006. Disponível em: http://exporthelp.europa.eu/thdapp/comext/ComextServlet ?languageId=EN. Acesso em: set. 2006.

KUME, H.; MIRANDA, P.; PIANI, G.; CASTILHO, M.R. Acordo de Livre-Comércio MERCOSUL-União Européia: uma estimativa dos impactos no comércio brasileiro. Rio de Janeiro: IPEA, 2004. 34p. (Texto para Discussão, n. 1054).

LAIRD, S.; YEATS, A. Quantitative methods for trade-barrier analysis. New York: New York University, 1990.

MACIENTE, A.N. A formação de um acordo de livre-comércio entre o MERCOSULe a União Européia: uma análise comparada. 2000. Dissertação (Mestrado em Economia) - Universidade de São Paulo, São Paulo.

MINISTÉRIO DO DESENVOLVIMENTO, INDÚSTRIA E COMÉRCIO EXTERIOR (MDIC). Aliceweb. Brasília, 2006. Disponível em: http://aliceweb.desenvolvimento.gov.br/alice.asp/alice.asp. Acesso em: 18 fev. 2006.

WAQUIL, P.W.; ALVIM, A.M.; SILVA, L.X.; TRAPP, G.P. Vantagens comparativas reveladas e orientação regional das exportações agrícolas brasileiras para a União Européia. Revista de Economia e Agronegócios, Viçosa, 2004. 